\title{
Management of Patients With Hepatitis C in a Community Population: Diagnosis, Discussions, and Decisions to Treat
}

\author{
Liliana Gazzuola Rocca, MD \\ Barbara P. Yawn, MD, MSc' \\ Peter Wollan, $P b D^{1}$ \\ W. Ray Kim, MD, $M B A^{2}$ \\ 'Department of Clinical Research, Olmsted \\ Medical Center, Rochester, Minn
}

${ }^{2}$ Department of Gastroenterology and Hepatology, Mayo Clinic, Rochester, Minn

\begin{abstract}
BACKGROUND Chronic hepatitis C, a treatable condition caused by the hepatitis C virus (HCV), can be found in almost all primary care and community practices. The rate of hepatitis $C$ treatment is low, however. This study explores the frequency of hepatitis $C$ treatment, documented discussions of treatment consideration, and the reasons treatment may not be offered in a community population.

METHODS This study is a retrospective medical record review of care provided to all patients in Olmsted County, Minn, who had a confirmed diagnosis of hepatitis C. Using all records from all health care providers in Olmsted County, the rates of documented discussions regarding hepatitis $C$ treatment and the treatment rates by specialty of diagnosing physician were assessed. In addition, comorbidities listed as reasons not to treat and or comorbid conditions in patients without a documented treatment discussion were assessed.
\end{abstract}

RESULTS Of the 366 patients with hepatitis C, 62\% were men. Hepatitis C was more commonly diagnosed by generalist physicians (41\% of cases). Treatment discussions were documented for $77 \%$ of patients with hepatitis C diagnosed by either a generalist or a gastrointestinal specialist (gastroenterologist or hepatologist) compared with $46 \%$ of patients with hepatitis C diagnosed by other physicians. Generalists' patients were more likely to have documented contraindications to treatment and were only one half as likely to receive hepatitis C treatment compared with patients with hepatitis C diagnosed by gastrointestinal specialists ( $16 \%$ vs $33 \%$ ). Documented attempts to treat or reassess after resolution of potentially reversible contraindications to hepatitis C therapy were infrequent.

CONCLUSIONS In this community population, hepatitis $C$ treatment was discussed with the majority of patients with a diagnosis of hepatitis $C_{\text {; }}$ however, the actual treatment rate was low. Many opportunities exist for treating more patients for HCV infection, particularly those found during emergency care and chemical dependency treatment. In addition, generalists' recognition and treatment of potentially reversible contraindications to hepatitis C therapy could greatly increase the number of treatment candidates.

Ann Fam Med 2004;2:116-124. DOI: 10.1370/afm.62.

\section{INTRODUCTION}

Conflicts of interest: none reported

\section{CORRESPONDING AUTHOR:}

Barbara Yawn, MD, MSc

Department of Research

Olmsted Medical Center

210 Ninth Street SE

Rochester, MN 55904

Yawnx002@umn.edu
$\mathrm{H}$

epatitis $\mathrm{C}$ is a chronic, often asymptomatic blood-borne infection first identified in the early 1990s. Up to 4 million Americans are believed to be infected with this indolent disease. ${ }^{1-3}$ An estimated $20 \%$ to $25 \%$ of infected persons progress to cirrhosis or hepatocellular carcinoma within 20 years of infection. ${ }^{4}$ Other infected persons remain asymptomatic for decades with no evidence of progression and normal or minimally elevated liver function tests. ${ }^{5,6}$ Hepatitis $\mathrm{C}$ currently accounts for $40 \%$ of all chronic liver disease, $20 \%$ to $30 \%$ of all liver transplantations, and more than 8,000 deaths each year. ${ }^{3}$ 
Treatment is recommended for all $\mathrm{HCV}$-infected persons with chronic progressive infection and is intended to reduce morbidity and mortality from cirrhosis and liver decompensation. ${ }^{7-9}$ Combination drug therapy and pegylated interferon have demonstrated increased rates of sustained viral response. ${ }^{10-18}$ Although it is too soon to assess the long-term (more than 5 years) impact of a sustained response to therapy, the high cost, limited access, and inconsistent outcomes of liver transplantation in patients with liver failure secondary to hepatitis $C$ highlights the importance of a treatment that may prevent progression of chronic hepatitis C. ${ }^{18-24}$

Despite advances in therapy for hepatitis $C$, not all persons with hepatitis $\mathrm{C}$ receive or are eligible for treatment. Two recent studies report that only $28 \%$ to $59 \%$ of patients with hepatitis $\mathrm{C}$ seen in specialized hepatology centers received treatment. ${ }^{25,26}$ Not all patients with hepatitis $C$ receive care in a hepatology clinic $^{27}$; however, and little is known about patients with hepatitis $\mathrm{C}$ in community practices and whether they have rates of treatment similar to those of patients referred to hepatology centers. It is possible that referral bias might produce higher rates of treatment among patients seen in specialty centers.

This study evaluates rates of documented treatment discussions, contraindications to treatment, treatment rates, and sustained viral response rates in a community-based population of persons with physician-diagnosed hepatitis $C$. This new communitybased information should guide programs designed to increase rates and success of hepatitis $\mathrm{C}$ therapy among primary care patients.

\section{METHODS}

This study was a retrospective medical record review of all medical care provided to all persons listed in the Olmsted County Hepatitis C Registry. ${ }^{27,28}$ The registry includes all Olmsted County residents with a physician diagnosis of hepatitis $C$ from January 1,1990, through December 31, 2000. Medical record abstraction from all sites of care within Olmsted County was used to determine rates of hepatitis $C$ treatment, documented discussions or consideration of hepatitis $C$ treatment, contraindications to treatment, and treatment response.

\section{Setting}

Olmsted County, Minn, is a metropolitan statistical area of approximately 120,000 residents and includes the city of Rochester. The county is 90 miles south of Minneapolis and St. Paul, medically isolated, and surrounded by rural agricultural land. Olmsted County residents are served by 2 medical facilities, the Olmsted Medical Center and the Mayo Clinic, which pro- vide primary and tertiary inpatient and outpatient care locally. For this study of adults, generalists or primary care physicians are defined as family physicians and general internists.

\section{Subjects}

The population of patients with hepatitis $C$ has been described previously. ${ }^{27,28}$ Briefly, the diagnostic index of the Rochester Epidemiology Project was used to identify all residents of Olmsted County who had diagnostic codes potentially consistent with a diagnosis of hepatitis $\mathrm{C}$ or non-A/non-B hepatitis (ICD-9 codes 070.51, 070.41, 070,42, V02.62,070.54, 070.44, 571.40,

$571.49,573.0)$. After receiving approval from the Olmsted Medical Center and the Mayo Clinic institutional review boards, each potential registry patient who had provided general research authorization, as required by Minnesota statute, was linked to all sites where he or she received any medical care in Olmsted County from 1990 to the present using the Rochester Epidemiology Project index. ${ }^{29,30}$ This system is reported to capture $98 \%$ of all health care for all Olmsted County residents. ${ }^{30}$ Only patients who did not refuse the general research authorization required by Minnesota statute were included.

All medical records for each potential registry patient were reviewed, and the patient was entered into the registry if a diagnosis of hepatitis $C$ could be confirmed. From 1990 to 2000, the criteria for including patients in the registry were updated as new tests became available, eg, second-generation enzyme immunoassay and polymerase chain reaction tests for HCV. Not all patients had a complete evaluation by the current standards. Overall, $8.5 \%$ had only a positive $\mathrm{HCV}$ test plus risk factors or elevated liver function tests; 55.5\% had positive $\mathrm{HCV}$ and recombinant immunoblot assay (RIBA) tests; $36.0 \%$ had positive HCV, RIBA, and polymerase chain reaction tests. Patients who were positive for $\mathrm{HCV}$ and who had negative RIBA findings, a normal liver function test, and no risk factors were considered to be falsely positive for hepatitis $\mathrm{C}$ and not included. Patients whose original diagnosis was non-A/ non- $B$ hepatitis were included only if they had positive HCV-specific tests.

For this study specific data were abstracted for each person in the registry. Data collected included information on the initial hepatitis $C$ diagnostic process, the specialty of the physician who first made the diagnosis (or ordered the hepatitis C diagnostic tests), all follow-up visits related to hepatitis $\mathrm{C}$, and risk factors for $\mathrm{HCV}$ infection as documented in the medical records. In addition, data were collected on all laboratory data related to hepatitis $\mathrm{C}$ (ie, liver function tests, $\mathrm{HCV}$ tests, RIBA, polymerase chain reaction, viral load). 
All information on treatment, including type of therapy, duration of therapy, and reasons therapy was discontinued, were also abstracted. Response to therapy was recorded in terms of relapse and no response or sustained viral response. Sustained viral response was defined as 6 or more months of normal alanine aminotransferase levels (when polymerase chain reaction was not available) or 6 or more months of negative polymerase chain reaction findings after completion of therapy. These definitions are consistent with the recent National Institute of Health 2002 consensus conference on hepatitis $\mathrm{C}$ therapy. ${ }^{31}$

Patients who did not receive therapy were further divided into those with a documented consideration of treatment and those with no documented treatment consideration. For those with no documented discussion, information on all comorbidities were recorded, including conditions that are considered potential contraindications to therapy. ${ }^{31}$ This information was used to define irreversible contraindications to treatment (conditions that were not amenable to treatment or that were likely to be fatal in 3 to 5 years even if treated) and those conditions that resolve with time (eg, pregnancy) or might be amenable to treatment or intervention or vary with time (eg, alcoholism, drug dependency, lack of health insurance). The second category was designed to identify potential opportunities to intervene and increase the number of patients eligible for hepatitis $\mathrm{C}$ therapy. Persons were placed in these categories based on the consensus of the study physicians (LR, BY, WK).

\section{Data analysis}

Demographic and risk factor data were summarized with means and ranges. Frequencies were compared across subgroups using chi-square, Kruskal-Wallis tests, or Fisher exact tests.

\section{RESULTS}

Of the 366 patients in the registry, $38 \%$ were women and $62 \%$ were men. The average age at diagnosis was 40 years (range 0.3 to 82.3 years) with 3 patients younger than 6 years old. The community prevalence of physician-diagnosed hepatitis C was estimated to be $0.19 \%$ (95\% confidence interval $(\mathrm{CI})$ $0.16 \%-0.21 \%)$. Patients had documented risk factors similar to those reported in the medical literature, including $43 \%$ with reported current or past intravenous drug use (Table 1$){ }^{32}$

Almost two thirds $(\mathrm{n}=234$, $64 \%$ ) of the 366 registry patients had a discussion or a consideration of hepatitis $C$ treatment recorded in their medical records, including the 55 (15\%) who received treatment. Documented treatment discussions and treatment were more likely to occur for white (non-Hispanic) patients with more than a high school education and for patients who did not have a history of cocaine use $(P=.0005)$. Discussions of treatment and treatment were almost universal among those whose only documented risk factor was "health care worker." Patient age and sex were not associated with rates of documented treatment discussions or treatment $(P \geq 19)$ (Table 1$)$.

Generalist physicians (gen- 
Table 2. Hepatitis C Discussions and Treatment by Source of Diagnosis

\begin{tabular}{|c|c|c|c|c|}
\hline \multirow[b]{2}{*}{$\begin{array}{l}\text { Source of Initial } \\
\text { Diagnosis }\end{array}$} & \multirow[b]{2}{*}{$\begin{array}{c}\text { Total } \\
(\mathrm{N}=366) \\
\text { No. (Column \%) }\end{array}$} & \multirow[b]{2}{*}{$\begin{array}{c}\text { Treated } \\
(n=55) \\
\text { No. }(\text { Row \%) }\end{array}$} & \multicolumn{2}{|c|}{ Not Treated } \\
\hline & & & $\begin{array}{c}\text { Discussed } \\
(\mathrm{n}=179) \\
\text { No. (Row \%) }\end{array}$ & $\begin{array}{c}\text { Not Discussed } \\
(n=132) \\
\text { No. (Row \%) }\end{array}$ \\
\hline Generalist & $149(41)$ & $24(16)$ & $91(61)$ & $34(36)$ \\
\hline Other physicians & $88(24)$ & $12(14)$ & $34(39)$ & $42(48)^{*}$ \\
\hline $\begin{array}{l}\text { Psychiatrist or chemical } \\
\text { dependency treatment } \\
\text { center }\end{array}$ & $47(13)$ & $1(2)^{\dagger}$ & $23(49)$ & $23(49)^{*}$ \\
\hline $\begin{array}{l}\text { Gastroenterologist, } \\
\text { hepatologist }\end{array}$ & $33(9)$ & $11(33)^{\dagger}$ & $15(45)$ & $7(21)$ \\
\hline Hospital & $22(6)$ & $0^{+}$ & $8(36)$ & $14(64)^{*}$ \\
\hline Blood bank & $17(5)$ & $7(41)^{\dagger}$ & $6(35)$ & $4(24)$ \\
\hline Emergency department & $10(3)$ & $0^{+}$ & $2(20)$ & $8(80)^{*}$ \\
\hline
\end{tabular}

stated prevented treatment, and others refused therapy at that time $(\mathrm{n}=23)$. Altogether 80 of the 179 patients had documented contraindications that might be amenable to therapy or resolved by finding additional resources, and an additional 23 said they might reconsider therapy at a later time.

Many patients with irreversible contraindications to hepatitis $\mathrm{C}$ therapy received their diagnosis from general- eral internists and family physicians) diagnosed $41 \%$ of cases, more than any other specialty group. Gastrointestinal specialists (gastroenterologists and hepatologists) diagnosed $9 \%$ of cases, and $5 \%$ of cases were diagnosed as a result of blood bank screening (Table 2). The percentages of patients with documented discussion or consideration of hepatitis $\mathrm{C}$ treatment (whether treated or not) were similar for generalists (77\%), gastrointestinal specialists (78\%), and blood banks (76\%) (percentages equal those in column 2 plus column 3 in Table 2). Patients whose hepatitis $\mathrm{C}$ was diagnosed in the emergency department, by mental health professionals (usually in the context of admission to a chemical dependency or mental health treatment facility), or by specialty physicians other than a gastroenterologist or hepatologist were less likely to have discussions of treatment documented in their medical records $(<52 \%)$ (Table 2).

Untreated persons with a documented consideration of treatment $(\mathrm{n}=179)$ had a variety of reasons documented for not receiving treatment, including 19 who had normal liver tests and who were not considered candidates for therapy, ${ }^{31} 11$ with end-stage liver disease, 3 with end-stage complications of human immunodeficiency virus infection, and 28 with other life-threatening comorbidities (Table 3). The life-threatening comorbidities were a combination of malignancies and renal and cardiac conditions likely to result in death within 3 to 5 years (Table 3 ) plus 1 person with incapacitating migraine headaches that were believed to make therapy unfeasible. Other patients had comorbidities, such as alcoholism $(\mathrm{n}=34)$ and depression $(\mathrm{n}=25)$, that were potentially treatable or conditions that resolve with time (eg, pregnancy, $n=3$ ). An additional group of patients had inadequate financial resources and no available clinical trials $(n=15)$ or a language barrier $(n=3)$ that the physician ists, and most (except the 11 patients with end-stage liver disease) were not referred to a gastrointestinal specialist. Patients with potentially reversible contraindications were seen by all specialty groups. Patients with potentially reversible contraindications either did not have documented attempts to treat the potentially reversible contraindication or any notation of reassessing treatment eligibility after treatment or resolution of the comorbid condition or financial situation. None who initially refused therapy were reassessed when new treatments became available.

The remaining 132 patients had no documented

Table 3. Documented Reasons for Not Treating Hepatitis C in 179 Patients

\begin{tabular}{|c|c|}
\hline Reason & No. $(\%)$ \\
\hline Alcohol and drug abuse with or without depression* & $34(19)$ \\
\hline Severe comorbidity ${ }^{\dagger}$ & $28(16)$ \\
\hline Depression without chemical dependency* & $25(14)$ \\
\hline Refused - no further specifications & $23(13)$ \\
\hline ALT, AST normal levels (NIH guidelines 1997) & $19(11)$ \\
\hline No trial available, no money, no insurance* & $15(8)$ \\
\hline Old age $(70-85$ y) & $12(7)$ \\
\hline End-stage liver disease or cirrhosis & $11(6)$ \\
\hline Pregnant at diagnosis, treatment not reconsidered* & $3(2)$ \\
\hline End-stage HIV infection, with or without hemophilia & $3(2)$ \\
\hline Severe language barrier* & $3(2)$ \\
\hline Acute hepatitis C & $3(2)$ \\
\hline Total ${ }^{\ddagger}$ & $179(100)$ \\
\hline \multicolumn{2}{|c|}{$\begin{array}{l}\text { ALT = alanine aminotranserase; AST = aspartate aminotransferase; } \mathrm{NIH}= \\
\text { National Institutes of Health; HIV = human immunodeficiency virus. }\end{array}$} \\
\hline \multicolumn{2}{|c|}{ * Potentially reversible comorbidities, $\mathrm{n}=80$} \\
\hline \multicolumn{2}{|c|}{$\begin{array}{l}\text { Comorbidities include malignancies under treatment, previous cardiac or renal } \\
\text { transplant, ongoing renal dialysis, diabetes with severe complication, vasculitis, } \\
\text { multiple sclerosis-progression, ulcerative colitis, debilitating migraine headache, } \\
\text { aortic aneurysm. }\end{array}$} \\
\hline ₹ The 179 patients represent $49 \%$ of the total 366 study patier & \\
\hline
\end{tabular}




\section{Table 4. Comorbid Conditions Recorded in 132 Patients With No Documented Hepatitis C (HVC) Treatment Discussions}

\begin{tabular}{|c|c|}
\hline Comorbid Condition & No. $(\%)$ \\
\hline Severe comorbidity* & $42(32)$ \\
\hline $\begin{array}{l}\text { No discussion of HCV tests in medical record, patient } \\
\text { may be unaware of HCV status }{ }^{\dagger}\end{array}$ & $31(24)$ \\
\hline Died before treatment considered & $24(18)$ \\
\hline Financial barriers mentioned related to other problems ${ }^{\dagger}$ & $13(10)$ \\
\hline Chronic schizophrenia or other psychotic conditions & $8(6)$ \\
\hline Old age (70 to 85 y) & $3(2)$ \\
\hline Children (0 to 6 y) & $3(2)$ \\
\hline Pregnant at diagnosis, treatment not reconsidered ${ }^{\dagger}$ & $3(2)$ \\
\hline Unable to speculate regarding reasons & $4(3)$ \\
\hline Severe depression with suicide attempt & $1(1)$ \\
\hline Total $^{\ddagger}$ & $132(100)$ \\
\hline \multicolumn{2}{|c|}{$\begin{array}{l}\text { * End stage acquired immunodeficiency syndrome, leukemia, hepatocellular } \\
\text { carcinoma, diabetes with severe neuropathy, renal rejection after transplant, liver } \\
\text { rejection after transplant, rapidly progressive autoimmune disorder, stage IV } \\
\text { cardiac disease. }\end{array}$} \\
\hline $\begin{array}{l}\text { f Potentially remediable conditions } n=47 \\
\text { f The } 132 \text { patients represent } 36 \% \text { or of the total } 366 \text { study pati }\end{array}$ & \\
\hline
\end{tabular}

discussion of treatment in their medical records. More than one third ( $\mathrm{n}=57,38 \%$ ) of these patients had lifethreatening conditions that likely made them ineligible for treatment, including human immunodeficiency virus infection, acute leukemia, hepatocellular carcinoma, diabetes complicated by severe neuropathy, renal or cardiac transplant rejection, or severe autoimmune diseases at the time or within months of the date of hepatitis $\mathrm{C}$ diagnosis (Table 4). Also included were 6 who were either younger than 6 years or older than 70 years. Most patients without a documented treatment discussion were not referred to a gastrointestinal specialist.

Several of the patients with no documented consideration of hepatitis $C$ treatment never had a visit in which their hepatitis $\mathrm{C}$ status was recorded by a physician or nurse $(n=31,23 \%)$. These patients included 8 who had hepatitis $\mathrm{C}$ diagnosed during an emergency department visit or hospitalization for major trauma requiring emergency surgery, and 23 who were seen almost exclusively in the emergency department for alcohol or drug-related intoxication or suicidal ideation that resulted in hospitalization in mental health or chemical dependency units of the hospital. It is not clear from the medical records that these patients were aware of their hepatitis $C$ status.

Three women were pregnant at the time of the hepatitis $\mathrm{C}$ diagnosis and had no documented discussion regarding treatment after the delivery. The final 13 appeared to have financial barriers to medical treatment, but no discussion was documented regarding the specifics of the financial barriers or consideration of potential solutions to these barriers. About one half $(n=68)$ of the 131 patients who were potential candidates for hepatitis $C$ treatment (Figure 1) were cared for by generalists. The 131 includes the 80 patients from the group with documented treatment consideration plus 51 from the group with no documented consideration of therapy. The 23 who refused therapy were not included as potential candidates but perhaps could be (Figure 1).

During the study period, 42 of the patients died, most from end-stage liver disease or other severe comorbidities. Thirty-eight who were potential treatment candidates were not included in the groups ${ }_{i}$ however, the 4 patients who died traumatically from murder $(\mathrm{n}=1)$ and suicide $(\mathrm{n}=3)$ were included (Table 5$)$.

A total of 55 adults $(15 \%)$ received treatment for hepatitis C (37 men and 18 women). Sixteen percent of patients $(\mathrm{n}=24)$ whose hepatitis $\mathrm{C}$ was diagnosed by a generalist received treatment compared with $33 \%$ $(\mathrm{n}=11)$ of the patients who had hepatitis $\mathrm{C}$ diagnosed by a gastrointestinal specialist. Of the 55 patients receiving treatment, 21 (38\%) had a sustained viral response. The treatments documented during the 10-year period included interferon alone ${ }_{i}$ interferon and ribavirin ${ }_{i}$ interferon, ribavirin, and etanercept (research protocol only), or interferon, ribavirin, and interleukin (research protocol only); and more recently pegylated interferon and ribavirin. In addition to the 21 patients with a sustained viral response, another 21 patients (38\%) were nonresponders, and $13(24 \%)$ discontinued treatment before a response, most because of side effects.

\section{DISCUSSION}

In this community population, generalists diagnosed more cases of hepatitis $C$ than any other group of physicians, including the gastroenterologists and hepatologists, affirming that it is often the generalist who begins the hepatitis $\mathrm{C}$ care process. Almost two thirds of patients with a diagnosis of hepatitis $\mathrm{C}$ had at least 1 documented discussion regarding treatment. Both generalists and gastrointestinal specialists were equally likely to discuss treatment, but generalist physicians appeared to deal with patients who had more comorbid conditions and more irreversible contraindications to treatment than did the gastrointestinal specialists.

A higher percentage of the patients who had hepatitis $\mathrm{C}$ diagnosed by a gastrointestinal specialist received therapy than did those who had hepatitis $\mathrm{C}$ diagnosed by a generalist. This finding affirms the referral bias of generalist physicians filtering out the patients with complex or serious nonhepatic conditions, choosing to refer those more likely to be eligible for treatment of hepatitis $\mathrm{C}$ to the gastrointestinal specialist. These differences in patient characteristics highlight the problem with gener- 
Figure 1. Management and disposition of community-dwelling patients with hepatitis C.

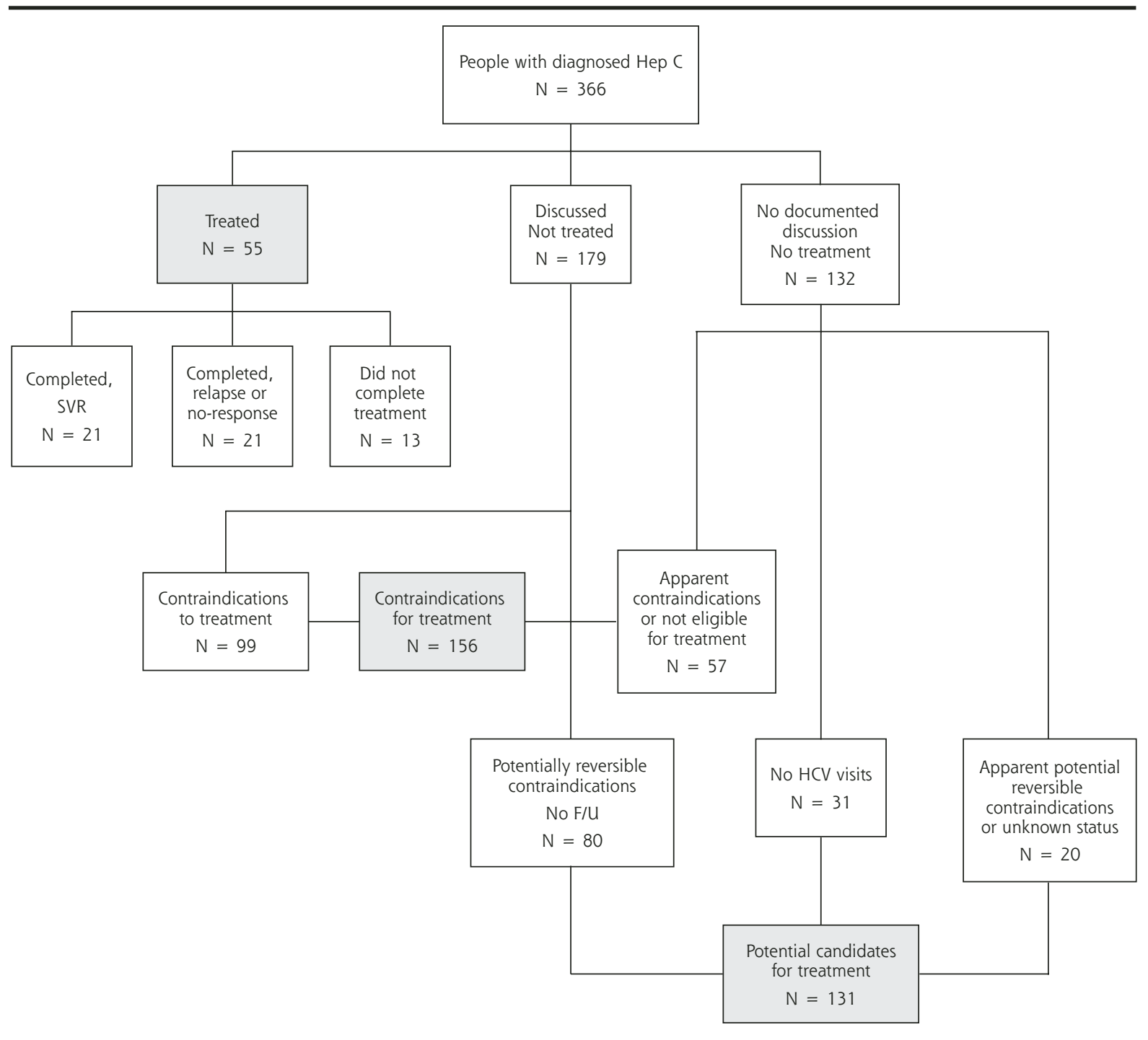

Hep C = hepatitis $C_{i}$ SVR = sustained viral response; F/U = follow-up; HCV = hepatitis $C$ virus.

alizing from hepatology clinic data reported in previous studies to the general population. ${ }^{25,26}$ This referral bias must be considered when comparing management and outcomes of patients cared for by generalist and hepatology specialist physicians.

Two recent studies based in hepatology clinics of teaching hospitals report rates of hepatitis C treatment eligibility of $28 \%$ and $59 \% .^{25,26}$ In these university clinic studies, patients considered ineligible for treatment included those with absolute contraindications to treatment, such as end-stage liver disease or diseases resulting in short life expectancies (ie, malignancies), plus patients who were pregnant, those who refused treatment, and those with active alcoholism and depression. Although these latter patients were considered to be ineligible at the time of the gastrointestinal specialist consultation, their health problems and personal choices can change with time. Consequently, some of the tertiary care center criteria for contraindications, such as active alcoholism, depression, and treatment refusal, can represent potentially reversible contraindications. Neither of the hepatology clinic-based studies acknowledged that chemical dependency or depression are potentially amenable to treatment or that patients refusing treatment might change their minds when newer treatments or better insurance is available to them. Consideration of the potential temporal changes in eligibility is particularly important to the generalists, who provide continuity of care for months or years.

In Olmsted County, 36\% of the patients (Figure 1) 


\begin{tabular}{|c|c|c|c|c|}
\hline \multirow[b]{2}{*}{ Cause of Death } & \multirow[b]{2}{*}{$\begin{array}{c}\text { Total } \\
(\mathrm{n}=42)\end{array}$} & \multirow[b]{2}{*}{$\begin{array}{l}\text { Treated } \\
(n=4)\end{array}$} & \multicolumn{2}{|c|}{ Not Treated } \\
\hline & & & $\begin{array}{l}\text { Discussed } \\
(n=14)\end{array}$ & $\begin{array}{l}\text { Not Discussed } \\
\quad(n=24)\end{array}$ \\
\hline $\begin{array}{l}\text { End-stage liver disease or } \\
\text { hepatocellular carcinoma }\end{array}$ & 17 & 2 & 6 & 9 \\
\hline $\begin{array}{l}\text { Cardiovascular diseases } \\
\text { (CHF, MI, stroke) }\end{array}$ & 8 & 1 & 3 & 4 \\
\hline Cancer & 4 & 0 & 0 & 4 \\
\hline Murder or suicide & 4 & 0 & 2 & 2 \\
\hline $\begin{array}{l}\text { Infectious diseases } \\
\text { (pneumonia, AIDS) }\end{array}$ & 3 & 0 & 0 & 3 \\
\hline Others & 6 & 1 * & $3+$ & $2 \ddagger$ \\
\hline \multicolumn{5}{|c|}{$\begin{array}{l}\text { CHF = congestive heart failure; } \mathrm{MI}=\text { myocardial infarction; AIDS = acquired immunodeficiency syndrome. } \\
\text { * Amyotrophic lateral sclerosis. } \\
\text { † Chronic obstructive pulmonary disease, ruptured cardiac aneurysm (Marfan syndrome), seizure disorder- } \\
\text { severe tetraplegia-suffocation. } \\
\text { † Renal failure. }\end{array}$} \\
\hline
\end{tabular}

reversible contraindications were treated ( $\mathrm{n}=131)$ and if all patients who initially refused therapy ( $\mathrm{n}=$ 23) became treatment candidates, there might be as many as 59 additional patients with a sustained viral response or "cure." According to the current rate of sustained viral response in our population, for every 3 additional patients treated, 1 would be free of the HCV infection 1 year later.

The chronic care model $^{33}$ suggests that using information systems to develop a registry of patients with HCV infection could not only facilitate monitoring the progression of liver disease (if any) but also enhance the generalist's ability to

appeared to have irreversible contraindications to treatment of hepatitis $\mathrm{C}$ or life-threatening conditions that were associated with average survival of less than 3 to 5 years. Another 7\% were lost to follow-up or died shortly after the diagnosis and were considered ineligible or unknown. In addition to the $15 \%$ of patients who received treatment, another $36 \%(n=131)$ had potentially reversible or temporary contraindications, such as depression, active alcohol and drug abuse, lack of insurance, or pregnancy. Although addressing issues of active chemical dependency $(\mathrm{n}=34)$ and depression $(n=25)$ can be very challenging, these patients represent an opportunity for primary care physicians to decrease the size of the HCV-infected population considered ineligible for treatment. Treatment or referral for management and follow-up of such potentially reversible contraindications as depression, active alcoholism, or pregnancy might be addressed more comfortably by primary care physicians than hepatology specialists. The identification and management of these ongoing conditions highlights an important role for generalists in the management of hepatitis $\mathrm{C}$.

Admission to an inpatient chemical dependency treatment program was the cause of diagnosis for 20 patients. None had discharge notes or comments in future notes for primary care visits that included follow-up for hepatitis $\mathrm{C}$ and reconsideration of treatment after chemical dependency treatment. The pattern was similar for another 25 patients with a diagnosis of depression. These omissions point to an important opportunity to develop practice systems that enhance the ability of generalists and nonhepatology specialists to recognize, monitor, and, when appropriate, repeatedly offer therapy to alleviate contraindications of hepatitis $\mathrm{C}$ treatment. If all patients who had potentially follow the course of potentially reversible or resolvable contraindications. Such a system could also identify opportunities to link uninsured or underinsured patients with clinical trials that provide free or reduced cost care. Work is currently underway to make the Olmsted County Hepatitis C Registry available for clinical use. The new Health Insurance Portability and Accountability Act privacy requirements for sharing clinical data across health care systems might prevent this endeavor without additional patient permission.

The chronic disease model for improved patient outcomes is also based on the need to have informed patients. In this community population we found several patients $(n=31)$ who appeared to be unaware of their hepatitis $\mathrm{C}$ status. Most of these patients had blood tests for hepatitis $\mathrm{C}$ as part of an emergency department or preoperative evaluation. In the emergency department the test results were seldom available before the patient's discharge, and in the hospital the patient's hepatitis $\mathrm{C}$ status was usually not recorded in the discharge summary. In both cases no follow-up appointments to address the results of testing for HCV infection were included in the discharge planning.

In some states all HCV-positive tests are automatically reported to the local or state health department, and health workers are dispatched to patients' homes to assure that those with $\mathrm{HCV}$ infections are aware of their potential for infecting others. The impact of these direct state notification systems on hepatitis $\mathrm{C}$ monitoring and treatment rates should be studied. States such as Minnesota, where the system depends on clinician reporting, hospitals, emergency departments, and laboratories need to develop systems to assure that both the health department and patients are notified and that those with $\mathrm{HCV}$-positive tests receive at least minimal 
counseling. The early hepatitis $\mathrm{C}$ screening programs could serve as a model system. Patients whose only medical care occurs when they seek emergency care or detoxification are a unique challenge not well addressed by the usual system of care.

This study has several potential limitations. The use of the medical records to determine discussions or considerations of treatment assumes that the records reflect what occurs during the visit. Although other studies show that documented activities almost always occur, the errors of omission in documentation limit this methodology. ${ }^{34}$ It is therefore likely that the rate of documented discussions is a conservative estimate..$^{29,30}$

This cohort includes only physician-diagnosed hepatitis C. The calculated Olmsted County prevalence is about one tenth the rate reported for the Midwest by the National Health and Examination Survey (NHANES). ${ }^{32}$ NHANES data are based on universal serological screening of a volunteer population, therefore, the prevalence reported here is unlikely to reflect the entire population of $\mathrm{HCV}$-infected persons in $\mathrm{Olm}$ sted County. Systematic risk factor screening might identify additional persons with HCV infection and therefore additional candidates for hepatitis $C$ therapy.

The reported sustained viral response rate $(38 \%)$ in the 55 patients who received treatment is difficult to compare with the result of clinical trials because our patients received different kinds of treatment during the more than 10 years studied. Yet, our sustained viral response rate is encouraging compared with the 13\% sustained viral response rate reported by Falck-Ytter et al in their university-based hepatology clinic. ${ }^{25,26}$

The small amount of racial diversity in the Olmsted County population potentially limits the generalizability of the results. Even so, this predominantly white and rural population had hepatitis $\mathrm{C}$ risk factors comparable with more urban and racially diverse groups. ${ }^{32}$

\section{CONCLUSION}

The generalist is central to community-based hepatitis $\mathrm{C}$ management. The generalist's roles can include recognition of, screening for, and diagnosis of hepatitis $\mathrm{C}_{i}$ identification of, monitoring of, and treatment for potentially reversible treatment contraindications; and administration of or referral for hepatitis C-specific therapy.

\section{To read commentaries or to post a response to this article, see it} online at http://www.annfammed.org/cgi/content/full/2/2/116.

Key words: Hepatitis C, chronic; primary health care; community health planning

Submitted February 4, 2003; submitted, revised, May 15, 2003; accepted May 26, 2003.
Funding support: All authors received some salary support from an investigator-initiated research grant from Schering Plough Pharmaceuticals.

Acknowledgment: We appreciate the help of Carolyn Hain in preparation of this manuscript.

\section{References}

1. Recommendations for prevention and control of hepatitis $C$ virus $(\mathrm{HCV})$ infection and HCV-related chronic disease. MMWR. 1998;47(RR19): 1-23.

2. McQuillan G, Alter M, Moyer L, Lambert S, Margolis H. A population based serologic study of hepatitis $C$ virus infection in the United States. Am J Epidemiol. 1996;143(suppl):S32.

3. Armstrong GL, Alter MJ, McQuillan GM, Margolis HS. The past incidence of hepatitis C virus infection; implications for the future burden of chronic liver disease in the United States. Hepatology. 2000;31:777-82.

4. Liang TJ, Rehermann B, Seef LB, Hoofnagle JH. Pathogenesis, natural history, treatment, and prevention of hepatitis C. Ann Intern Med. 2000;132:296-305.

5. Wong JB, Bennett WG, Koff RS, Pauker SG. Pretreatment evaluation of chronic hepatitis C. JAMA. 1998;280:2088-2093.

6. Wright T, Jeffers L, Mitchell T, Holohan TV, Kizer KW. At war with hepatitis C, part 3: managing chronic infection. Federal Practitioner. 2000; 17:24-30.

7. Schiff ER, De Medina M, Kahn RS. New perspectives in the diagnosis of hepatitis C. Semin Liv Dis. 1999;19:3-15.

8. Vial T, Descotes J. Clinical toxicity of the interferons. Drug Saf. 1994; 10:115-150.

9. Tanaka H, Tsukuma H, Kasahara A, et al. Effect of interferon therapy on the incidence of hepatocellular carcinoma and mortality of patients with chronic hepatitis C: a retrospective study of 738 patients. Int J Cancer. 2000;87:741-749.

10. McHutchison JG, Gordon SC, Schiff ER, et al. Interferon alfa-2b alone or in combination with ribavirin as initial treatment for chronic hepatitis C. Hepatitis Interventional Therapy Group. N Engl J Med. 1998;339:1485-1492.

11. Poynard T, Marcellin P, Lee SS, et al. Randomized trial of interferon alpha $2 \mathrm{~b}$ plus ribavirin for 48 weeks or for 24 weeks versus interferon alpha $2 \mathrm{~b}$ plus placebo for 48 weeks for treatment of chronic infection with hepatitis C virus. International Hepatitis Interventional Therapy Group (IHIT). Lancet. 1998;352:1426-1432.

12. Davis GL, Balart LA, Schiff ER, et al. Treatment of chronic hepatitis $C$ with recombinant interferon alfa. A multicenter randomized, controlled trial. Hepatitis Interventional Therapy Group. N Engl J Med. 1989;321:1501-1506.

13. Poynard T, McHutchison J, Goodman Z, Ling MH, Albrecht J. Is an "a la carte" combination interferon alfa- $2 b$ plus ribavirin regimen possible for the first line treatment in patients with chronic hepatitis C? Hepatology. 2000;31:211-218.

14. Zeuzem S, Franke A, Lee JH, Herrmann G, Ruster B, Roth WK. Phylogenetic analysis of hepatitis $C$ virus isolates and their correlation to viremia, liver function tests, and histology. Hepatology. 2000;24: 1003-1009.

15. Zeuzem S, Feinman SV, Rasenack J, Heathcote EJ, Lalman J, Brunda MJ. Peginterferon alfa-2a in patients with chronic hepatitis C. N Engl J Med. 2000;343:1666-1672.

16. Fried MW, Shiffman ML, Reddy KR, et al. Pegylated interferon alfa-2a in combination with ribavirin: Efficacy and safety results from a phase III, randomized, actively controlled, multicenter study [abstract]. Gastroenterology. 2001;120:A55. 
17. Mannis MP, McHutchison JG, Gordon Sc, et al. Peginterferon alfa-2b in combination with ribavirin compared with interferon alfa-2b plus ribavirin for initial treatment of chronic hepatitis C: results of a randomized trial. Lancet. 2002;359:263.

18. Poynard T, McHutchison J, Davis GL, et al. Impact of interferon alfa- $2 \mathrm{~b}$ and ribavirin on progression of liver fibrosis in patients with chronic hepatitis C. Hepatology. 2000;32:1131-1137.

19. Wiesner RH, Demetris AJ, Belle $S$, et al. Acute hepatic allograft rejection: Incidence, risk factors and impact on outcome. Hepatology. 1998;28:638-645.

20. Wright TL, Donegan E, Hsu HH, et al. Recurrent and acquired hepatitis $C$ viral infection in liver transplant recipients. Gastroenterology. 1992; 103:317-322.

21. Chazouilleres O, Kim M, Combs C, et al. Quantitation of hepatitis C virus RNA in liver transplant recipients. Gastroenterology. 1994;106: 994-999.

22. Barcena R, Del Camp S, Sanroman AL, et al. Prospective study of hepatitis $C$ virus infection after orthotopic liver transplantation. Transplant Proc. 1997;29:515-516.

23. Gane EJ, Naomov NV, Qian KP, et al. A longitudinal analysis of hepatitis $C$ virus replication following liver transplantation. Gastroenterology. 1996;110:167-177.

24. Firpi RJ, Abdelmalek MF, Soldevila-Pico C, et al. Combination of interferon alfa-2b and ribavirin in liver transplant recipients with histological recurrent hepatitis C. Liver Transpl. 2002;8:1000-1006.

25. Falck-Ytter Y, Kale H, Mullen KD, Sarbah SA, Sorescu L, McCullough AJ. Surprisingly small effect of antiviral treatment in patients with Hepatitis C. Ann Intern Med. 2002;136:288-292.
26. Kinzie JL, Naylor PH, Ehrinpreis MN, et al. Reluctance of urban clinic patients to undergo treatment with interferon-alpha [abstract]. Hepatology. 1999;30:266A.

27. Yawn BP, Wollan P, Gazzuola L, Kim WR. Diagnosis and 10-year follow-up of a community-based hepatitis C cohort. J Fam Pract. 2002;51:135-140.

28. Yawn BP, Gazzuola L, Wollan PC, Kim WR. Development and maintenance of a community-based hepatitis C registry. Am J Manag Care. 2002;8:253-261.

29. Kurland LT, Molgaard CA. The patient record in epidemiology. Sci Am. 1981;245:54-63.

30. Melton LJ III. History of the Rochester Epidemiology Project. Mayo Clin Proc. 1996;71:266-274.

31. Davis GL. NIH Consensus Conference on the Management of Hepatitis C: 2002 part 3. Utilization of virologic testing in the treatment of chronic hepatitis C. Available at: http://www.hcvadvocate.org/ nihconf3.htm. Accessed November 25, 2002.

32. Alter MJ, Kruszon-Moran D, Nainan OV, et al. The prevalence of hepatitis C virus infection in the United States, 1988 through 1994. N Eng J Med. 1999;341:556-562.

33. Bodenheimer T, Wagner EH, Grumbach K. Improving primary care for patients with chronic illness. JAMA. 2002;288:1775-1779.

34. Stange KC, Zyzanski SJ, Smith TF, et al. How valid are medical records and patient questionnaires for physician profiling and health services research? A comparison with direct observation of patient visits. Med Care. 1998;36:851-867. 